\title{
KEBAKARAN HUTAN DAN LAHAN DI KALIMANTAN TAHUN 2019 (Refleksi atas Globalisasi dan Reduksi Kewenangan Pemerintah)
}

\author{
Oleh : \\ Safa Muzdalifah ${ }^{1)}$, Novy Setia Yunas ${ }^{2)}$ \\ ${ }^{1)}$ Program Studi Ilmu Pemerintahan,Universitas Lambung Mangkurat, Indonesia \\ ${ }^{2)}$ Program Studi Ilmu Politik, Universitas Brawijaya, Indonesia \\ E-mail : $\underline{\text { safa.muzdalifah@ulm.ac.id }}{ }^{1)}, \underline{\text { novysetiayunas@ub.ac.id }}{ }^{2)}$
}

\begin{abstract}
This article explores the influence of globalization to government authority a case study is Forest and Land Fires in Kalimantan 2019. This study as a verivicative research of the literature review, in order that the results are accept or ignore the thesis. The Result of this research is globalization has a close relation to government authority reduction, since the government disable to achieve the development economic target independently. This resutls proven by the exist of the regulation that increase the foreign investor come in to Indonesia and manage the strategic economics sector.
\end{abstract}

Keywords: Globalization, Government Authority, Forest and Land Fire, Kalimantan

\begin{abstract}
Abstrak
Artikel ini memverivikasi pengaruh globalisasi terhadap kewenangan pemerintah, dengan studi kasus kebakaran hutan dan lahan di Kalimantan pada tahun 2019. Penelitian ini merupakan penelitian kualitatif dengan jenis verivikatif yang bertujuan untuk menolak atau menerima hasil peneltian sebelumnya. Hasil penelitian ini ditemukan bahwa globalisasi mengakibatkan tereduksinya kewenangan pemerintah. Hal ini dibuktikan dengan menelaah kebakaran hutan dan lahan di Kalimantan yang terjadi di tahun 2019. Fenomena tersebut terjadi berawal dari adanya regulasi pemerintah yang mendorong aliran modal asing masuk ke Indonesia dengan wadah PT.PMA. Regulasi ini menjamin pihak swasta untuk mendapatkan izin konsesi hutan di Indonesia yang sebelumnya dikelola oleh negara. Atas kondisi tersebut kewenangan pemerintah berkurang, dan dampaknya bukan saja percepatan ekonomi namun deforestasi secara luas.
\end{abstract}

Kata Kunci : Globalisasi, Kewenangan Pemerintah, Kebakaran Hutan dan Lahan, Kalimantan

\section{PENDAHULUAN}

Globalisasi adalah keniscayaan. (Scholte: 2001) Kemajuan ilmu pengetahuan dalam teknologi informasi dan komunikasi membawa dunia kepada suatu keadaan saling terhubung antara satu negara dengan negara lainnya, bahkan menjadi satu kesatuan secara alamiah. Perkembangan teknologi dan informasi ini mengakibatkan penyempitan ruang dan waktu antar negara, sehingga hubungan antar negara menjadi lebih intens dan bervariasi. Tidak satupun negara dapat menghindari dan berlomba-lomba untuk dapat beradaptasi agar tidak tertinggal 
dengan negara lainnya. Globalization connotes the stretching and intensification of social, economic and political relations across regions and continents. (Held,2002: 395) Peningkatan intensitas hubungan lintas batas ini berkembang diberbagai sektor baik sosial, ekonomi, hingga politik.

Atas kondisi tersebut, agar sebuah negara dapat bertahan, Hay (2008:316) menjelaskan bahwa hal yang perlu diidentifikasi adalah kapasitas negara, otonomi negara, dan kedaulatan negara itu sendiri. Berdasarkan hal tersebut, Waters (1995:124) berpendapat bahwa globalisasi mengakibatkan kekuasaan negara berkurang karena negara tidak mampu mengatasi seluruh permasalahan dalam negerinya secara mandiri. Di satu sisi, Hirst dan Thompson (1999: 256) meyakini bahwa negara merupakan entitas utama dalam menjalankan kekuasaan. Berdasarkan perbedaan pandangan tersebut, penulis sepakat terhadap pernyataan Waters bahwa globalisasi telah mereduksi kewenangan pemerintah dalam mengelola suatu negara. Oleh karena itu, pertanyaan penelitian ini adalah bagaimana globalisasi mereduksi kewenangan pemerintah?

\section{METODE PENELITIAN}

Didalam menjawab suatu persoalan penelitian, maka diperlukan metode penelitian yang tepat. Menurut Sugiono (2012) metode penelitian adalah:

$$
\begin{aligned}
& \text { "Metode penelitian } \\
& \text { merupakan cara ilmiah untuk } \\
& \text { mendapatkan data yang valid } \\
& \text { dengan tujuan dapat } \\
& \text { ditemukan, dibuktikan, dan } \\
& \text { dikembangkan suatu } \\
& \text { pengetahuan sehingga pada } \\
& \text { gilirannya dapat digunakan } \\
& \text { untuk memahami, } \\
& \text { memecahkan, dan } \\
& \text { mengantisipasi masalah". }
\end{aligned}
$$

Penelitian ini menggunakan metode kualitatif. Menurut Creswell (1998) penelitian kualitatif adalah suatu penyelidikan untuk memahami suatu hal dengan menggunakan tradisi metodologi penyelidikan yang mengeksplorasi masalah-masalah sosial, yang menghasilkan data kualitatif. Lebih khusus penelitian ini merupakan penelitian verivikatif (verivicative research), yang bertujuan untuk menguji suatu hasil penelitian, sehingga diperoleh hasil yang menolak atau mendukung penelitian sebelumnya. (Sugiono:2013) Pengujian ini dilakukan dengan analisis studi kasus yang menghadirkan fakta-fakta pendukung rumusan hipotesis. Dalam hal ini peneliti akan menguatkan hasil penelitian sebelumnya yang menjelaskan bahwa 
globalisasi berpengaruh terhadap terjadinya reduksi kewenangan pemerintah. Studi kasus yang digunakan adalah kebakaran hutan dan lahan di Kalimantan pada tahun 2019. Variabel penelitian ini adalah komponen-komponen yang terdapat di dalam globalisasi sebagai variabel independen dan kewenangan pemerintah baik pusat dan daerah yang berkaitan dengan pengelolaan hutan di Kalimantan sebagai variabel dependen. Jenis data yang digunakan adalah data sekunder, dan teknik pengumpulan datanya adalah studi pustaka.

\section{HASIL DAN PEMBAHASAN}

Dewasa ini perkembangan ekonomi suatu negara tidak terlepas dari gagasan kapitalisme global. Menurut Karl Marx kapitalisme adalah suatu sistem yang menempatkan harga barang dan kebijakan pasar ditentukan oleh pemilik modal agar memperoleh keuntungan maksimal. Menurut Adam Smith kapitalisme adalah sistem yang dapat menciptakan kesejahteraan bagi masyarakat negara jika pemerintah tidak mengintervensi kebijakan dan mekanisme pasar. Dalam artian kepentingan bersama dapat diperhatikan dengan baik jika kepentingan individu mendapat kesempatan untuk memenuhi dan mengekspresikan kepentingannya tanpa restriksi. Menurut Max Weber kapitalisme adalah sistem ekonomi yang berlaku pada suatu pasar dan dipacu untuk menghasilkan keuntungan dengan kegiatan tukar menukar di pasar tersebut. Berdasarkan ketiga pendapat tersebut, dapat ditarik garis lurus bahwa pada dasarnya kapitalisme adalah sebuah sistem ekonomi yang yang lebih berorientasi pada pemenuhan kebutuhan ekonomi secara individu, pembagian porsi peran lebih banyak kepada individu di sektor ekonomi, dan berkuasanya modal.

$$
\text { Jangkauan kapitalisme telah }
$$
berkembang keseluruh negara dengan jaringan lintas batas negara atau yang disebut kapitalisme global. Perluasan jaringan secara global tidak terlepas dari berkembangnya teknologi informasi dan komunikasi, yang memfasilitasi hubungan antar lintas negara menjadi semakin mudah. Ruang lingkup pasar tidak hanya pada skala domestik namun telah meluas secara global, demikian juga aliran modal bergerak secara global. Kondisi ini tidak hanya berlaku bagi negara maju, namun bagi negara yang sedang berkembang seperti Indonesia.

Wajah Indonesia berubah setelah disahkannya Undang-Undang No. 1 tahun 1967 tentang penanaman modal asing. Dalam Pasal 5 dijelaskan bahwa: 
"Penanaman modal asing adalah meliputi penanaman modal asing secara langsung yang dilakukan menurut atau berdasarkan ketentuanketentuan Undang-undang ini dan yang digunakan untuk menjalankan perusahaan di Indonesia, dalam arti bahwa pemilik modal secara langsung menanggung risiko dari penanaman modal tersebut".

Undang-Undang ini dibuat dengan pertimbangan bahwa upaya untuk penanggulangan kemunduran ekonomi serta pembangunan tidak boleh menimbulkan keseganan untuk memanfaatkan teknologi, skill, dan modal yang berasal dari luar negeri, bahkan sedapat mungkin meminimalisir keraguraguan pihak modal asing. Penanaman modal asing diyakini dapat mempercepat pembangunan ekonomi nasional.

Selain itu terdapat paket 6 Mei 1986. Paket 6 Mei 1986 merupakan deregulasi melonggarkan izin impor barang modal dan penunjang, hingga pemakaian tenaga kerja asing. Deregulasi ini dikhususkan untuk investasi yang berorientasi ekspor atau membuka usaha di daerah. Paket ini kemudian dikuatkan kembali pada Paket Juni 1987 dan Paket Desember 1987. Demikian pula pada Peraturan Pemerintah No.20 tahun 1994 tentang pemilikan saham dalam perusahaan yang didirikan dalam rangka penanaman modal asing. Pada Peraturan Pemerintah ini diatur ketentuan jaminan kelangsungan penanaman modal asing dalam bentuk pendirian perusahaan penanaman modal asing yang berbentuk Perseroan Terbatas di Indonesia.

Seiring bertambahnya tahun, penanaman modal asing memperoleh prioritas daripada penanaman modal dalam negeri. Kesenjangan ini tertuang dalam Undang-Undang No. 25 Tahun 2007 tentang Penanaman Modal untuk menggantikan Undang-Undang Penanaman Modal Asing No. 1 Tahun 1967 dan Undang-Undang Penanaman Modal Dalam Negeri No. 6 Tahun 1968. Pada undang-undang terbaru tersebut sektor strategis yang menguasai hajat hidup orang banyak dapat dikuasai secara mayoritas oleh modal asing dan Pemberian hak istimewa melalui perjanjian dengan negara.

Dampak dari regulasi yang dirumuskan pemerintah adalah meningkatnya aliran modal asing ke Indonesia dan menguatnya peran swasta dalam sektor-sektor strategis negara. Pada 
tahun 2019 aliran modal asing masuk ke Indonesia senilai 224,2 triliun. Uni Eropa secara konsisten menjadi investor utama non Asia dengan aliran Penananman Modal Asing Langsung (FDI) senilai US\$
1,8 milyar pada tahun 2018. Berikut ini data perbandingan realisasi PMA dan PMDN pada tahun 2019:

Tabel 1. Realisasi PMA dan PMDN di Indonesia pada Tahun 2019

\begin{tabular}{|l|l|l|l|l|l|l|l|l|}
\hline \multirow{2}{*}{ Periode } & \multicolumn{4}{|c|}{ PMA (Trliun Rupiah) } & \multicolumn{3}{c|}{ PMDN (Triliun Rupiah) } \\
\cline { 2 - 9 } & Primer & Sekunder & Tersier & Total & Primer & Sekunder & Tersier & Total \\
\hline Q2 2018 & 21,22 & 38,13 & 47,77 & 107,12 & 20,4 & 24,8 & 35,4 & 80,57 \\
\hline Q1 2019 & 12,54 & 28,10 & 67,28 & 107,92 & 18,28 & 16,09 & 52,81 & 87,19 \\
\hline Q2 2019 & 14,99 & 38,19 & 51,71 & 104,88 & 21,77 & 22,20 & 51,66 & 95,63 \\
\hline $\begin{array}{l}\text { Pertumbuhan } \\
\text { (QtQ) }\end{array}$ & 19,54 & 35,91 & $-23,14$ & $-2,82$ & 19,09 & 37,97 & $-2,18$ & 9,68 \\
\hline Pertumbuhan & $-29,36$ & 0,16 & 8,25 & $-2,09$ & 6,72 & $-10,48$ & 45,93 & 18,69 \\
(YoY) & 14,29 & 36,41 & 49,30 & 100 & 22,76 & 23,21 & 54,02 & 100 \\
\hline Proporsi (\%) & & & & & & & & \\
\hline
\end{tabular}

Sumber: Badan Koordinasi Penanaman Modal (diolah) dalam Kementerian PPN/Bappenas 2019

Berdasarkan data tersebut, realisasi PMA dan PMDN pada setor utama menunjukkan nilai PMA lebih besar daripada PMDN. Hal tersebut berlaku bagi seluruh kategori sektor utama di Indonesia yakni baik sektor primer, tersier, dan sekunder. Realisasi PMA pada triwulan II ada tahun 2019 adalah sebesar USD6.992,31 juta. Nilai ini menurun sebesar 2,09\% dibandingkan dengan periode yang sama di tahun 2018. Berdasarkan komposisi antarsektor, realisasi PMA didominasi oleh sektor tersier yakni sebesar 51,71 persen.

Selain itu, dalam pengelolaan lahan, luas lahan yang dimilik Badan Usaha Milik Negara (BUMN) cenderung menetap jumlahnya dan semakin 
berkurang. Terjadi peningkatan luas lahan rakyat yang lebih besar dari yang dimiliki BUMN. IGJ (2014) dalam menyebutkan bahwa Tahun 2003 luas perkebunan negara adalah 1.086.355 ha, kepemilikan swasta atas perkebunan kelapa sawit adalah 2.765.504 ha, luas area perkebunan Oil Palm adalah 645.823 ha dan untuk karet (Rubber) 221.472 ha, sedangkan luas perkebunan kelapa sawit yang dimiliki BUMN adalah 1.827.844 ha dan perkebunan karet seluas 2.797.192 ha.

Melalui data tersebut, dapat diidentifikasi bahwa ekspansi swasta atas sumber daya yang menguasai hajat hidup orang banyak sangat laju perkembangannya. Hal tersebut tidak menguntungkan bagi negara, karena akan mengurangi hasil keuntungan dari sumber daya yang seharusnya diserap oleh negara, mengurangi kekuasaan negara dalam pengelolaan dan pengawasan, tidak memberikan jaminan pelindungan kepada pengembangan Badan Usaha Milik Negara (BUMN), dan ancaman eksploitasi secara masif. Kekuatan modal yang dimiliki swasta jauh melampau negara. Dalam hal ini negara dimasa mendatang akan menghadapi persoalan yang pelik karena kontrol negara semakin berkurang dan harus dilakukan tindakan pencegahan.
Disahkannya Undang-Undang tersebut juga mencakup regulasi pengelolaan hutan dan lahan di Indonesia. Pemerintah menghendaki pengelolaan hutan dilakukan dengan mengusung GFD (good forest governance). Good Forest Governance adalah konsep yang diyakini sebagai sebuah strategi yang dapat mengakomodir dinamika dan menjawab berbagai persoalan dalam pengelolaan sumberdaya hutan. Dalam konsep ini negara hendaknya memahami kekurangannya dalam pengelolaan hutan, sehingga negara harus share roles and authorities kepada stakeholders terkait kapasitasnya. Pada konteks ini pemerintah yang selama ini dinilai memgang kekuasaan penuh atas pengeolaan hutan, secara signifikan memberikan sebagian kekuasaannya kepada aktor bukan negara.

Di dalam implementasinya, yang terjadi tidak seideal gagasan Good Forest Governance, melainkan terjadi Land Use, Land Use Change and Forestry (LULUCF) secara sigifikan dan di luar kendali pemerintah. Penggunaan lahan, perubahan penggunaan lahan, dan kehutanan mengubah postur dan kontur kehutanan. Ekosistem hutan yang secara mendasar befungsi untuk menjaga keseimbangan lingkungan global telah mengalami banyak alih fungsi baik pemukiman, industri, hingga perkebunan. 
Alih fungsi ini bukan saja mengurangi luas hutan secara masif dan merusak ekosistem, namun menimbulkan kerusakan lanjutan seperti banjir, longsor, perubahan iklim secara ekstrim, dan kebakaran hutan.

Indonesia merupakan laboratorium kerusakan hutan yang tepat untuk diamati. Indonesia adalah negara dengan bentang alam yang sangat luas yang terletak di garis khatulistwa. Kondisi ini memberikan karakteristik tersendiri sebagai negara dengan hutan hujan tropis terbesar kedua setelah Brazil. Seluruh daratan Indonesia semula merupakan wilayah yang tertutup hutan, kecuali lereng-lereng yang terjal dan jalur-jalur pesisir yang sempit. (FWI: 2011) Dinas Kehutanan Indonesia menyebutkan bahwa Indonesia pada tahun 1950, 84\% (164 juta ha) luas daratannya tertutup hutan primer. (dalam FWI: 2011) Wilayah tutupan hutan terluas di Indonesia adalah di Kalimantan. Luas tutupan hutan di Kalimantan adalah 51.400.000 ha pada tahun 1950. Wilayah ini terdiri dari hutan hujan primer, hutan lindung, hutan rawa, hutan rimba seluas 47.500.000 ha, hutan pantai: 700.000 ha, dan hutan sekunder: 3.200.000 ha. Dibandingkan dengan tiga pulau besar di Indonesia, luas lahan tutupan hutan Kalimantan unggul, yakni Sumatera: $\quad 37.370 .000$ ha, Sulawesi: 17.050.000 ha, dan Irian Jaya: 40.700.000 ha. (Dinas Kehutanan, Jakarta. Dalam:
International Institute for Environment and Development \& Government of Indonesia. 1985. Forest Policies in Indonesia. The Sustainable Development of Forest Lands. Jakarta, 30 November. Volume III)

Deforestasi semakin masif di Kalimantan. Berdasarkan data dari World Bank, pada tahun 1900 asumsi tutupan hutan seluas 17.500.000 ha, Tahun 1985 seluas 11.111.900 ha, Tahun 1997 seluas 4.707.800 ha, dan menghasilkan estimasi kehilangan secara keseluruhan seluas 6.404 .100 ha atau $58 \%$ selama kurun waktu tersebut. (Holmes, D. 2000. Deforestation in Indonesia: A Review of the Situation in 1999. Jakarta: World Bank) Pada tahun 2016-2019 deforestasi terus berlangsung, Kalimantan mengalami deforestasi tertinggi di Indonesia yakni 132,7 ribu atau $27,6 \%$.

Deforestasi dampak dari alih fungsi hutan yakni komersialisasi lahan tutupan hutan. Komersialisasi lahan tutupan hutan adalah proses pengelolaan hutan untuk perdagangan berorientasi profit. Komersialisasi hutan Indonesia masif sejak tahun 1970-an. Alih fungsi hutan menjadi perkebunan, pertanian, dan pengambilan kayu sebagai hasil hutan. Pembukaan hutan secara besar-besaran menyebabkan kebakaran hutan ekstrim. 
Berikut ini rekapitulasi kebakaran hutan

2014-2019.

dan lahan (ha) di Kalimantan sejak tahun

Tabel 2. Rekapitulasi Kebakaran Hutan dan Lahan (ha) di Kalimantan sejak Tahun 2014-2019

\begin{tabular}{|l|c|c|c|c|c|c|}
\hline \multicolumn{1}{|c|}{ Provinsi } & $\mathbf{2 0 1 4}$ & $\mathbf{2 0 1 5}$ & $\mathbf{2 0 1 6}$ & $\mathbf{2 0 1 7}$ & $\mathbf{2 0 1 8}$ & $\mathbf{2 0 1 9}$ \\
\hline Kalimantan Barat & $3.556,10$ & $93.515,80$ & $9.174,19$ & $7.47,33$ & $68.422,03$ & $127.462,00$ \\
\hline Kalimatan Selatan & 341,00 & $196.516,77$ & $2.331,96$ & $8.290,34$ & $98.637,99$ & $113.454,00$ \\
\hline Kalimantan Tengah & $4.022,85$ & $583.833,44$ & $6.148,42$ & $98.637,99$ & $47.432,57$ & $134.227,00$ \\
\hline Kalimantan Timur & 325,19 & $69.352,96$ & $43.136,78$ & $47.432,57$ & $27.893,20$ & $50.056,00$ \\
\hline Kalimantan Utara & - & $14.506,20$ & $2.107,21$ & 627,71 & 627.71 & $2.878,00$ \\
\hline
\end{tabular}

Sumber : Direktorat PKHL Kementerian Lingkungan Hidup dan Kehutanan RI

\section{https://www.sipongi.menlhk.go.id}

Berdasarkan tabel tersebut, dari tahun ke tahun degradasi hutan terus meningkat. Pada tahun 2019 merupakan tahun dengan hutan dan lahan terbakar terluas di Kalimantan. Di tahun 2019 mencapai 428.077,00 ha, 2018: 242.385,79 ha, 2017 46.11,3 ha, dan 2016: 62.898,56 ha. Pada tahun 2019 kebakaran hutan meningkat $86,288 \%$ dari tahun 2018. Lahan Terbakar sepanjang JanuariSeptember 2019857.756 ha, yang terdiri dari 630.451 Ha Lahan Mineral dan 227.304 Ha Lahan Gambut.

Kebakaran hutan ini terjadi secara tersistem. Pembakaran dilakukan oleh perusahaan-perusahaan pemegang izin konsesi hutan. Berdasarkan data dari 8| Jurnal Public Corner Fisip Universitas Wiraraja
Kementerian Kehutanan dan Lingkungan Hidup, perusahaan pemegang izin konsesi hutan selain perusahaan lokal juga termasuk perusahaan penanaman modal asing. Perusahaan penanaman modal asing merupakan perusahaan yang modalnya merupakan investasi asing atau penggabungan dengan modal dalam negeri. Aliran modal asing ke Indonesia di tahun 1960-an praktis tidak ada, dan menguat sejak adanya UU No. 1 tahun 1967 tentang penanaman modal asing, Paket 6 Mei 1986 dan Pakto 1993, PP No.20 tahun 1994.

Kebakaran hutan di Kalimantan melibatkan perusahaan lokal dan perusahaan penanaman modal asing. PT. 
PMA mendominasi, antara lain di Kalimantan Barat, melibatkan PT. SKM (Sukses Karya Mandiri) milik Malaysia, PT. ABP (Aneka Bumi Pratama), PT. Artu Energi Resourse (AER) milik Malaysia, PT. HKI (Hutan Ketapang Industri) milik Singapura, PT.SI (Sime Indoagro) milik Malaysia, PT. SKS (Sukses Karya Sawit) milik Malaysia, dan PT. RKA (Rafikamajaya Abadi) milik Malaysia. (Kementerian Lingkunga Hidup:2019) Selain itu, di Kalimantan Tengah terdapat PT. ABP (Aneka Bumi Pratama), PT. Ikhtiar Gusti Pudi (IGP), PT. Rafi Kamajaya Abadi (RKA), dan PT. Artu Energi Resourse (AER) yang dimiliki oleh Malaysia, dan PT. AUS milik Singapura. (Kementerian Lingkungan Hidup:2019)

Perusahaan penanaman modal asing dominan dalam kontribusinya terhadap kebakaran hutan di Kalimantan pada tahun 2019. Secara umum didominasi oleh penanam modal yang berasal dari asia. Kolaborasi antara perusahaan swasta dalam negeri dan asing memberikan kemampuan tambahan untuk mengembangkan usaha. Kepemilikan modal yang besar dengan area pengelolaan yang sangat luas berbanding lurus dengan jangkauan eksploitasi sumber daya alam yang dilakukan.

\section{PENUTUP}

Kebakaran hutan dan lahan di Kalimantan pada Tahun 2019 menjadi sebuah refleksi bahwa globalisasi menyebabkan terjadinya reduksi kewenangan pemerintah. Kerusakan hutan sekaligus dampak lanjutan yang ditimbulkan tidak terjadi begitu saja. Kondisi ini muncul sejak Indonesia mulai mengikuti arus globalisasi secara masif. Kemajuan teknologi informasi dan komunikasi mendorong negara-negara untuk beradaptasi dalam fenomena integrasi global. Perilaku ini terjadi tidak hanya pada negara maju namun juga negara yang sedang bekembang. Perilaku adaptasi ini dilakukan dalam bentuk penyesuaian secara fundamental yakni melalui disahkannya produk hukum yang menjadi pijakan pemerintah dalam mengelola negara.

Indonesia merupakan salah satu negara dengan adaptasi yang sangat signifikan. Secara bertahap Indonesia menyesuaikan dengan keadaan global, yakni melalui rumusan dasar-dasar hukum yang memudahkan Indonesia untuk menarik aliran modal asing masuk ke Indonesia. Dibuatlah regulasi yang bertujuan menjamin kemudahan aliran modal asing masuk ke Indonesia. Salah satunya adalah dengan disahkannya 
Undang-Undang No. 1 tahun 1967 tentang Penanaman Modal Asing (PMA). PT.PMA memiliki kapasitas kuat dan luas untuk mendapakan izin konsesi hutan, yang sebelumnya dikelola oleh negara. Kebijakan bersahabat dengan modal asing diambil karena Indonesia tidak mampu untuk memenuhi target pemerintahan secara mandiri dan membutuhkan aktor hubungan internasional lainnya. Target yang dimaksud adalah percepatan pertumbuhan ekonomi secara signifikan. Kondisi ini mendorong pemerintah untuk melakukan kerjasama ataupun kolaborasi dengan kapitalis global.

Eksistensi PT. PMA menjelaskan berbagai hal, pertama bahwa kekuatan korporasi dalam pengelolaan aset negara yang menguasai hajat hidup orang banyak sangat besar, jaminan pemerintah terhadap pengelolaan PT. PMA lebih kuat daripada perusahaan milik negara, perputaran aliran modal asing di Indonesia lebih dominan daipada aliran modal dalam negeri, resiko atau dampak negatif yang menyertainya juga dalam skala besar, dan hak pengelolaan hutan yang menjadi tanggung jawab pemerintah tereduksi, bahkan kontrol pemerintah terhadap aktifitas PT.PMA juga rendah. Hal ini dibuktikan dengan penguasaan wilayah yang diperuntukkan bagi hajat hidup orang banyak didominasi oleh swasta, terjadi deforestasi, serta bencana kebakaran hutan dan lahan.

\section{DAFTAR PUSTAKA}

\section{Buku}

Al-Rodhan, R.R. Nayef and Gerard Stoudmann, 2006 Definitions of globalization: A Comprehensive Overview and a Proposed Definition

Bridges, G, 2002: 361-386 Grounding Globalization: The prospects and Perils of Lingknt Economic Processes of Globalizaton to Environmental Outcomes

FWI, 2011, Potret Keadaan Hutan Indonesia Periode Tahun 20002009, Bogor: FWI

Haas, Peter M., 1989. "Do Regimes Matter? Epistemic Communities and Mediterranean Pollution Control". International Organization, 43 (3), pp. 377-403.

Hay, Colin, 2008, Globalization's Impact on States”. Dalam John Ravenhill ed., Global Politcal Economiy, Oxford: Oxford University Press, pp.314-345.

Held, David et. al. 1999. "Catastrophe in the Making: Globalization and the Environment", dalam Global Transformations: Politics, Economics and Culture. Stanford: 
Stanford University Press, pp. 376413.

Hirst, Paul.I\& Thompson, Grahame, 1999,

"Globalization, Governance and the Nation-State" Cambridge : Polity, 256-280

Sugiono, 2012, Metode Penelitian Kuantitatif Kuaitatif dan $R \& D$, Bandung: Alfabeta.

Waters, Malcom, 1995, "Wither the State? Globalizing Politics", dalam Globalization, London: Routledge, pp.123-159

\section{Jurnal}

Direktorat PKHL Kementerian Lingkungan Hidup dan Kehutanan RI

https://www.sipongi.menlhk.go.id

International Institute for Environment and Development \& Government of Indonesia. 1985. Forest Policies in Indonesia. The Sustainable Development of Forest Lands. Jakarta, 30 November. Volume III Indonesia for Global Justice, 2014, Negara VS Korporasi, ModulBITS_Indonesia

Kementerian PPN/Bappenas, 2019, Perkembangan Ekonomi Indonesia dan Dunia Triwulan II 2019, Edisi Vol. 3 No.2 Agustus 2019 